\title{
A função social das rádios-postes do Nordeste do Brasil ${ }^{1}$
}

\author{
Giovana MESQUITA ${ }^{2}$ \\ Izani MUSTAFÁ ${ }^{3}$
}

\begin{abstract}
Resumo:
$\mathrm{O}$ rádio no Brasil comemorou 101 anos de existência em 2020, considerando as primeiras experimentações realizadas pela Rádio Club de Pernambuco, em 1919. Com mais de cem anos de existência, o rádio no Brasil tem se reinventado nas últimas décadas com o emprego de tecnologias digitais e o surgimento na internet de novas plataformas e suportes. Apesar disso, nota-se que modelos mais tradicionais e analógicos, como as rádioscomunitárias e as rádios-postes, subsistem e se mantêm relevantes em determinados contextos sociais e determinadas regiões, como o Nordeste. Assim, neste artigo, reflete-se sobre como rádios-postes atuantes no Nordeste do Brasil cumprem uma importante função social e aproximam-se, em termos de finalidade e produção, das rádios comunitárias. Para desenvolver a reflexão, foi realizada uma revisão bibliográfica sobre o tema, com enfoque na atuação de duas experiências com rádios-postes em Imperatriz (MA): a Caema e a Salimp. Considerase que as experiências, além de promoverem a cultura local, acenam para a possibilidade de democratização da comunicação.
\end{abstract}

Palavras-chave: rádio; rádio-poste; rádios comunitárias; Nordeste; função social.

\section{The social function of community audio towers in the Northeast of Brazil}

\begin{abstract}
:
Radio in Brazil celebrated 101 years of existence in 2020, considering the first experiments carried out by Rádio Club de Pernambuco, in 1919. With over a hundred years of existence, radio in Brazil has been reinventing itself in recent decades with the use of digital technologies and the emergence of new platforms and supports for the internet. Despite this, it is noted that more traditional and analogue models, such as community radios and audio towers, subsist and remain relevant in certain social contexts and in certain regions, such as the Northeast. Thus, this article reflects on how community audio towers operating in the Northeast of Brazil fulfill an important social function and come closer, in terms of purpose and production, to community radios. To develop this reflection, a literature review on the subject was carried out, focusing on the performance of two experiments with community audio towers in Imperatriz (MA): Caema and Salimp. We believe that the experiences, in addition to promoting local culture, point to the possibility of democratizing communication.
\end{abstract}

Keywords: radio; community audio tower; community radios; Northeast; social role.

1 Trabalho apresentado no GT História da Mídia Sonora, integrante do $11^{\circ}$ Encontro Nacional de História da Mídia, realizado de 19 a 21 de junho de 2019, em Natal (RN), revisado e ampliado. Este artigo foi elaborado com o apoio da Coordenação de Aperfeiçoamento de Pessoal de Nível Superior - Brasil (CAPES) - FINANCE CODE 001.

2 Doutora em Comunicação Social pela Universidade Federal de Pernambuco (UFPE). Professora adjunta do curso de Comunicação do Centro Acadêmico do Agreste e vice-coordenadora do Programa de Pós-Graduação em Comunicação, ambos da UFPE. Vice-coordenadora da Pós-Graduação em Comunicação Política da UFPE.

E-mail: giovana.mesquita@ufpe.br

3 Doutora em Comunicação Social pela Pontifícia Universidade Católica do Rio Grande do Sul (PUCRS). Professora adjunta da graduação e da Pós-Graduação em Comunicação/Jornalismo da Universidade Federal do Maranhão, campus Imperatriz. E-mail: izani.mustafa@gmail.com. 


\title{
La función social de las radios poste del noreste de Brasil
}

\begin{abstract}
Resumen:
La radio en Brasil celebró 101 años de existencia en 2020, considerando los primeros experimentos realizados por Rádio Club de Pernambuco, en 1919. Con más de cien años de existencia, la radio en Brasil se ha reinventado en las últimas décadas con el uso de tecnologías y la aparición de nuevas plataformas y soportes para Internet. Pese a ello, se observa que modelos más tradicionales y analógicos, como las radios comunitarias y las radios poste, subsisten y siguen siendo relevantes en determinados contextos sociales y en determinadas regiones, como el Noreste. Así, este artículo reflexiona sobre cómo las radios poste que operan en el Noreste de Brasil cumplen una función social importante y se acercan, en términos de finalidad y producción, a las radios comunitarias. Para desarrollar esta reflexión, se realizó una revisión de la literatura sobre el tema, enfocándose en la realización de dos experimentos con radios poste en Imperatriz (MA): Caema y Salimp. Creemos que las experiencias, además de promover la cultura local, apuntan a la posibilidad de democratizar la comunicación.
\end{abstract}

Palabras clave: radio; radio poste; radio comunitária; noreste; papel social.

Há mais de 100 anos, o início....

O rádio no Brasil existe há mais de 100 anos. Um dos marcos é a data 6 de abril de 1919, quando um grupo de radioamadores ligado à Associação de Amadores de Radio-Telegraphia criou, no Recife (PE), a Rádio Club de Pernambuco (MARANHÃO FILHO, 1991). Surgindo de forma experimental, para estudo das transmissões telegráficas e telefônicas sem fio, a pernambucana Rádio Clube foi ao ar, antes mesmo da demonstração de transmissões radiofônicas feita durante a Exposição Internacional do Centenário da Independência, em 1922, no Rio de Janeiro $(\mathrm{RJ})$. De lá para cá, o rádio sofreu muitas mudanças. Transformou-se e reinventou-se com as tecnologias e a Internet. As muitas mudanças passadas pelo rádio possibilitaram, por exemplo, que ele possa ser ouvido ao vivo pelo computador, pelo celular e por canais de TV por assinatura, sob demanda, bem como pelas plataformas de streaming e por meio das redes sociais (KISCHINHEVSKY, 2016).

No meio dessa evolução, convivem hoje o rádio que transmite em ondas hertzianas (AM e FM) e que também está na internet, além das rádios comunitárias e da rádio-poste. A diferença que destacamos no artigo entre a rádio-poste e a rádio comunitária reside, basicamente, na área de abrangência. Enquanto a primeira utiliza um transmissor que permite um alcance, no seu entorno, de no máximo um quilômetro, permitido pela Lei nº 9. 612 de 19 de fevereiro 1998, a segunda tem uma abrangência restrita a uma pequena comunidade, porque funciona por meio de caixas de som instaladas em postes. 
Os números sobre quantas rádios comunitárias existem no Brasil são controversos. O relatório da Agência Nacional de Telecomunicações de 2018 diz que existem no Brasil 4.872 rádios comunitárias autorizadas (ANATEL, 2018). De acordo com a Associação Mundial de Rádios Comunitárias, citada em matéria do site Brasil de Fato (DOLCE, 2018, não paginado), é possível que existam em torno de 12 mil emissoras comunitárias, entre autorizadas e não autorizadas, sem outorga. Em 2020, a agência de notícias Livre.Jor ${ }^{4}$ pediu acesso à informação ao Ministério da Ciência, Tecnologia, Inovações e Comunicações sobre o número de rádios comunitárias autorizadas a funcionar no Brasil. Em resposta, o órgão disse que são 4.607 distribuídas em 3.652 municípios brasileiros. A Livre.Jor alerta, na notícia publicada em 2 de junho de 2020, que isso "não significa que todas operam atualmente, mas visibiliza quem possui a licença, com o nome e o CNPJ de cada associação" (LÁZARO JÚNIOR, 2020, não paginado). Ao final da matéria foi divulgado um link para uma tabela com a relação das rádios comunitárias existentes no país. Já quanto ao número de rádios-postes existentes no Brasil é difícil quantificar, pela grandiosidade do país e as especificidades regionais.

Neste artigo, reflete-se sobre como rádios-postes cumprem uma importante função social e aproximam-se, em termos de finalidade e produção, das rádios comunitárias. Para abordar o tema, vamos focar na região Nordeste, fazendo uma revisão bibliográfica sobre rádios comunitárias e rádios-postes com estudos de Araújo (2011), Luz (2007, 2011), Brock e Malerba (2017), Malerba (2016) e Peruzzo (1998, 2005, 2009, 2010).

Em uma busca no Banco de Teses e Dissertações da Coordenação de Aperfeiçoamento de Pessoal de Nível Superior (Capes), localizamos três teses: "Rádios comunitárias no limite: crise na política e disputa pelo comum na era da convergência midiática", de João Paulo Malerba (2016); “As instituições comunitárias de ensino superior do Rio Grande do Sul: análise de sua importância para o desenvolvimento socioeconômico regional”, de Suzel Lisiane Jansen Bittencourt (2016); "Rádio comunitária e cidadania comunicativa: interações entre comunicadores, locutores e ouvintes das rádios comunitárias Lomba e a Voz do Morro", de Rodrigo Severo Rodenbusch (2018). Localizamos também uma dissertação: "Processos emancipatórios no MST: as rádios comunitárias”, de Ana Emília Barros Cardoso (2004).

\footnotetext{
4 A agência de notícias Livre.Jor está disponível no site: https://livre.jor.br/.
} 
Além da revisão bibliográfica sobre o tema, trazemos as leis de número 10.872/18 e 9.612/98 para discutir sobre os aspectos legais desse tipo de rádio. Por fim, o artigo mostra alguns exemplos de rádio-poste, como a Caema, que funciona na comunidade de mesmo nome, na cidade de Imperatriz (MA), onde as autoras do artigo já desenvolveram atividades de pesquisa e extensão, e uma experiência durante a realização do Salão do Livro de Imperatriz (Salimp), em 2019.

\section{História e alguns conceitos teóricos sobre rádio comunitária e rádio-poste...}

As rádios comunitárias surgiram na América Latina, no século 20, "para dar conta de desafios sociais e políticos com objetivos de promover alfabetização à distância, lutar por condições dignas de vida, restabelecer a democracia em contextos ditatoriais" (BROCK; MALERBA, 2017, p. 12). Em um segundo momento, essas emissoras foram surgindo dentro de diferentes comunidades para "ativar a consciência crítica da realidade, educar a partir de uma pedagogia libertadora, auxiliar na organização de movimentos sociais de base", lideradas, muitas vezes, pelas igrejas católicas (BROCK; MALERBA, 2017, p. 12-13).

No Brasil, segundo Peruzzo (1998), as primeiras experiências desse tipo de rádio eram denominadas de rádios livres, seguidas de denominações carregadas de conotações ideológicas, como rádios piratas, clandestinas ou ilegais, principalmente na década de 1970, quando elas se multiplicaram, forçando o Estado a criar uma regulamentação, instituída com a Lei n 9.612, de 19 de fevereiro de 1998.

Apesar de algumas estarem legalizadas, Peruzzo (2010) alerta que nunca existiu uma política pública para favorecer o trabalho delas dentro da comunidade. Em pleno século 21, as rádios comunitárias latino-americanas ainda vivem incertezas. Diz Malerba (2016):

Aquela conquista do poder foi acompanhada das decepções da real politik, que não tardaram a aparecer e a desferir mais um importante abalo nos fundamentos daquelas rádios: principalmente, por casos de cooptação política ou econômica, inalteração da repressão, ineficiência/ausência de políticas públicas de fomento e/ou abandono da histórica bandeira da democratização da comunicação (MALERBA, 2016, p. 21, grifo do autor).

Como bem pontua Malerba (2016), algumas rádios comunitárias, diante de uma falta de apoio cultural e sem recursos para manter uma infraestrutura técnica de qualidade, acabam 
sendo usadas para fins políticos, religiosos e com interesses econômicos, em troca de doações de computadores, softwares, microfones e espaço físico. Poucas comunitárias e rádios-postes mantêm sua função social, que, para Peruzzo (2010, p. 5), pelo próprio nome de comunitária, já deveria significar uma rádio que "transmite uma programação de interesse social vinculada à realidade local, não tem fins lucrativos, contribui para ampliar a cidadania, democratizar a informação, melhorar a educação informal”.

Segundo a pesquisadora, portanto, a rádio-poste, alternativa ou comunitária não é "um tipo qualquer de mídia”, mas é “como um processo de comunicação que emerge da ação dos grupos populares. Essa ação tem caráter mobilizador coletivo na figura dos movimentos e organizações populares, que perpassa e é perpassada por canais próprios de comunicação" (PERUZZO, 2009, p. 47). O estudioso Kaplún (1985, p. 7) salienta que o fenômeno da comunicação popular e alternativa é "uma comunicação libertadora, transformadora, que tem o povo como gerador e protagonista". Kaplún (1985) esclarece também que as mensagens produzidas nesse tipo de comunicação são feitas "para que o povo tome consciência de sua realidade" ou "para suscitar uma reflexão", ou ainda "para gerar uma discussão" (KAPLÚN, 1985, p. 17). Já Peruzzo (2009) entende que a rádio-poste, normalmente originando-se dentro de movimentos sociais, associações comunitárias, igrejas e entidades não governamentais, pode, sim, ter um objetivo de informar e contribuir para a educação e formação cidadã.

Assim como Kaplún e Peruzzo, acreditamos que o rádio é um importante instrumento "para uma educação popular, como alimentador de um processo educativo transformador" (KAPLÚN, 1985, p. 17). Principalmente porque, na maioria das vezes, esse tipo de comunicação atende comunidades de municípios que não possuem uma rádio voltada para a população local prestando serviço de interesse público.

Mas como toda atividade comunitária, também esse veículo de comunicação deve envolver a "participação popular autônoma, da gestão à produção de conteúdos", porque se trata de "uma comunicação destinada a atender demandas locais mediante o exercício da cidadania a partir dos próprios cidadãos. Suas diferenças em relação à mídia local comercial são claras, embora possa atuar no mesmo universo territorial e temático" (PERUZZO, 2005, p. 77). 


\section{A regulamentação da rádio-poste no Maranhão}

Em 19 de junho de 2018, o governador do Maranhão, Flávio Dino, então do Partido Comunista do Brasil (PCdoB) ${ }^{5}$ sancionou a Lei $\mathrm{n}^{\circ}$ 10.872, que regulamenta o serviço de rádioposte, fazendo valer o projeto de lei de autoria da deputada estadual Francisca Primo (PCdoB), aprovado na Assembleia Legislativa do Estado (SANCIONADA..., 2018). No Maranhão, existem em torno de 100 rádios-postes que serão beneficiadas com a regulamentação, porque cumprem as exigências para a legalização, conforme informação divulgado pelo governador Dino (MARANHÃO, 2018).

A lei sancionada pelo governador maranhense destaca, no Art. $3^{\circ}$., que o Serviço de Publicidade Alternativa de Linha Modulada (rádio-poste) tem por objeto

[...] a difusão sonora, com fins culturais, educacionais, de desenvolvimento do cooperativismo, do desenvolvimento local, regional e agrário, integrado e sustentável, do respeito ao meio-ambiente, de fins filantrópicos, assistenciais e de prestação de serviço de utilidade pública, com vistas a: a) Divulgar notícias e ideias, promover o debate de opiniões, ampliar informações culturais, de modo a manter a população bem informada; b) Integrar a comunidade por meio do desenvolvimento do espírito de solidariedade e responsabilidade comunitária, do incentivo à participação em ações de utilidade pública e de assistência social [...] (MARANHÃO, 2018).

A definição é muito similar ao que está disposto na Lei $n^{\circ}$ 9. 612, de 19 de fevereiro de 1998 - escrita, portanto, 20 anos antes - sobre o Serviço de Radiodifusão Comunitária:

Tem por finalidade o atendimento à comunidade beneficiada, com vistas a: IDar oportunidade à difusão de ideias, elementos de cultura, tradições e hábitos sociais da comunidade; II- Oferecer mecanismo à formação e integração da comunidade, estimulando o lazer, a cultura e o convívio social; III- Prestar serviços de utilidade pública, integrando-se aos serviços de defesa civil, sempre que necessário; IV-Contribuir para o aperfeiçoamento profissional nas áreas de atuação dos jornalistas e radialistas, de conformidade com a legislação profissional vigente; V- permitir a capacitação dos cidadãos no exercício do direito de expressão da forma mais acessível possível[...] (BRASIL, 1998).

É relevante perceber que as duas leis, $n^{\circ} 10.872$ e $n^{\circ}$ 9.612, reforçam a importância de as rádios-postes contribuírem para a formação do cidadão, ofertando informação de utilidade

\footnotetext{
${ }^{5}$ Flávio Dino migrou para o Partido Socialista Brasileiro (PSB) em 22 de junho de 2021.
} 
pública, cultural e social. Essas emissoras têm, no Nordeste e geralmente em cidades do interior do Brasil, uma função social, porque produzem conteúdos em áudio para comunidades que, às vezes, não têm acesso à informação produzida por outras mídias, como jornais e internet.

As rádios comunitárias tipo poste e as rádios comunitárias que transmitem em frequência modulada têm objetivos similares, apesar de funcionarem de forma distinta. Enquanto a regulamentação do Serviço de Publicidade Alternativa de Linha Modulada define que a rádio-poste, com transmissão via equipamentos sonoros, como alto-falante, fica restrita a algumas quadras no entorno do emissor (MARANHÃO, 2018), a rádio comunitária transmitida em frequência modulada é operada em baixa potência e tem uma cobertura restrita de até um quilômetro (BRASIL, 1998). Conforme a legislação do Maranhão, a rádio-poste não precisa de outorga e pode ser administrada por uma empresa individual ou grupo societário com fins comunitários. A comunitária depende de uma concessão outorgada a fundações e associações comunitárias, sem fins lucrativos, com sede na localidade da prestação de serviços da rádio.

Ambas podem contar com recursos advindos de apoio cultural para sua manutenção e não devem visar lucro. Com relação à programação das rádios-postes, a Lei no 10.872/2018 destaca que os programas devem, preferencialmente, ter conteúdos educativos, culturais, artísticos e informativos que contribuam com o desenvolvimento da comunidade (MARANHÃO, 2018). Também devem promover atividades artísticas e jornalísticas para integrar a comunidade; preservar os "valores éticos e sociais da pessoa humana e da família, de modo a fortalecer e bem integrar a comunidade; e coibir a discriminação de qualquer espécie e a qualquer título, seja de raça, religião, sexo, preferências sexuais e de convicções políticopartidárias ou ideológicas” (MARANHÃO, 2018).

Praticamente as mesmas orientações estão presentes no Art. $4^{\circ}$, que define a programação das rádios comunitárias FM. O último e quinto item citado nas duas leis é com relação a não "discriminação de qualquer espécie e a qualquer título, seja de raça, religião, sexo, preferências sexuais e de convicções político-partidárias ou ideológicas" (MARANHÃO, 2018).

A principal diferença entre os dois tipos de rádio é com relação à autorização para o seu funcionamento. No Maranhão, a rádio-poste depende da outorga para funcionamento, que é concedida pelo governo estadual, mediante alvará de localização e de funcionamento, conforme 
o Art. $6^{\circ}$ da Lei 10.872/2018 (MARANHÃO, 2018). Já a comunitária depende do governo federal para outorga à entidade que deseja explorar o Serviço de Radiodifusão Comunitária por três anos (BRASIL, 1998). A renovação pode ser solicitada por mais três anos, desde que as exigências da lei sejam cumpridas. E apenas as fundações e as associações comunitárias sem fins lucrativos e devidamente sediadas na área da comunidade onde vão prestar serviços podem explorar esse tipo de mídia, segundo o previsto no Art. $7^{\circ}$ da lei (BRASIL, 1998).

\section{Alguns casos de rádios-postes do Nordeste}

Sem dúvida, as rádios-postes e as rádios comunitárias têm um papel social dentro das comunidades em que são ouvidas, porque também preenchem os desertos de notícia da região onde não existem meios de comunicação como jornais, rádios e sites jornalísticos (ATLAS DA NOTÍCIA, 2020). De acordo com o Atlas da Notícia (2020), de um total de 5.570 cidades brasileiras, 3.487 municípios (62\%) não têm nenhum veículo jornalístico. E o Nordeste possui uma grande proporção de desertos de notícia em relação às demais regiões brasileiras. E é nesse cenário que o rádio na região é considerado a principal mídia, muito mais do que no restante do Brasil (ATLAS DA NOTÍCIA, 2020). Os casos de rádios-postes a seguir apresentam iniciativas que, em algum momento, fizeram a diferença para uma comunidade local.

A rádio-poste Cipó da cidade de João Lisboa, com um pouco mais 23.740 habitantes (IBGE, 2020) e a 12 quilômetros de distância de Imperatriz (MA), funciona numa sala pequena do proprietário Domingo Damaceno, numa casa perto de onde é realizada a feira livre, todos os sábados. De um jeito espontâneo, ele divulga algumas informações.

No segundo semestre de 2018, as estudantes do curso de Jornalismo da Universidade Federal do Maranhão, campus Imperatriz, Morgana Albuquerque e Yasmin Costa, desenvolveram o projeto de conclusão de curso denominado "Radiojornal Gameleira". O objetivo era contribuir com um informativo jornalístico de interesse público para ir ao ar no horário de maior movimentação na feira. As jovens produziram três edições do radiojornal, apresentadas ao vivo, que continham entrevistas com pessoas da comunidade, em sábados consecutivos: 27 de outubro, 3 e 10 de novembro de 2018. Cada informativo teve duração de quase uma hora, apresentado a partir de um roteiro elaborado. Como o foco era o público local, 
elas não tiveram dificuldades para narrar e apresentar as histórias de alguns personagens do município.

Outro caso envolve a rádio-poste da comunidade quilombola Maracujá, em Conceição do Coité, no território do sisal, na Bahia, instalada na Escola Municipal Emério Resedá (ASA BRASIL, s/d). A comunidade Maracujá conquistou a rádio-poste em 2017, por meio do projeto "Esportes Cooperativos: Inclusão Social, Construção de Saberes e Cidadania no Semiárido", do Movimento de Organizações Comunitárias (MOC), com apoio da Organização das Nações Unidas para a Educação, a Ciência e a Cultura (Unesco) e do Criança Esperança.

Jovens monitoras dos municípios de Santaluz e Retirolândia, vizinhos a Conceição do Coité, participaram de uma oficina que reuniu crianças e adolescente para debater sobre comunicação e a função da rádio-poste. Desse encontro foram produzidos três programas, chamados de Saberes do Maracujá, tendo crianças e adolescentes como entrevistadores, entrevistados, compositores de músicas e leitores de história. Os assuntos escolhidos foram as memórias do samba de roda, a preservação do lugar onde vivem e a história da comunidade. Os programas experimentais foram veiculados na rádio-poste como forma de socialização e de reconstituir e preservar a memória local.

Um terceiro caso é citado na monografia "Nas ondas de Mar Vermelho: um estudo de caso da rádio-poste 'Paz e Liberdade' do interior de Alagoas", de Pedro Ivo Nunes Almeida, defendida em 2010, na Universidade Federal de Viçosa (UFV), em Minas Gerais. No estudo, Almeida buscou compreender como se dá o processo comunicacional dos alto-falantes instalados na rua principal do município e observou como os moradores mais jovens se identificaram com o conteúdo transmitido pelas caixas de som instaladas nos postes. No trabalho, o estudante, que tinha integrado a equipe da UFV na operação Centro-Nordeste do Projeto Rondon, realizou uma pesquisa participante. Conforme Almeida (2010), a programação diária - destinada a aproximadamente 1.500 moradores da zona urbana de Mar Vermelho - é produzida pelo fundador do serviço de som, José Gomes de Lima, que sozinho coloca no ar o "Programa da tarde", reunindo música, informações de âmbito local e prestação de serviços. Almeida (2010, p. 50) destaca que a rádio-poste é tida pela comunidade como o "principal veículo de comunicação da cidade, a partir dela, fica-se sabendo das informações que têm relevância local”. 
Em 2016, Milena de Castro Ribeiro defendeu a dissertação "Rádio-Poste da Quadra: a participação dos moradores e as disputas sonoras em uma comunidade de Fortaleza", no Programa de Pós-Graduação de Comunicação da Universidade Federal do Ceará. O estudo é uma análise das relações "participativas e de convivência entre os moradores da comunidade São Vicente de Paulo (Quadra) e a rádio-poste Centro de Comunicação Alternativa, localizada no bairro Aldeota, em Fortaleza (Ceará)" (RIBEIRO, 2016, p. 8). A partir de uma pesquisa de campo e observações, ela fez uma reflexão sobre as formas de participação nos programas de dois grupos de moradores: os jovens católicos e as mulheres evangélicas. Ambos não entendiam a função de uma rádio como um meio de esclarecer e informar. Para a pesquisadora, a associação de moradores tem que valorizar a comunicação e incentivar a comunidade a apropriar-se da rádio para produzir notícias de interesse geral.

As quatro rádios-postes citadas cumprem o papel de informar, prestar um serviço e contribuir para a formação cidadã, narrando histórias de pessoas da comunidade local, gerando proximidade e identificação, suprindo a ausência de conteúdos jornalísticos de veículos tradicionais.

\section{Experiências da Rádio Caema e da Rádio Salimp em Imperatriz (MA)}

A rádio-poste da Caema está instalada na principal rua do bairro Caema, no Centro de Imperatriz, no Maranhão. Às margens do rio Tocantins, a Caema tem uma localização privilegiada e funciona numa comunidade originária de pescadores.

O discurso jornalístico unilateral da mídia hegemônica imperatrizense sobre o bairro divulga, em grande parte, apenas fatos policiais, narrados com base em relatos da polícia, esquecendo de pluralizar as demais fontes. A visibilidade do bairro em outros espaços jornalísticos, que não sejam os policiais, é bastante tímida, reforçando estigmas e preconceitos (MESQUITA, 2017).

Em 2012, a Organização Não Governamental Instituto de Projetos Educativos e Sociais (PES), que desenvolvia projetos ambientais no bairro, doou equipamentos para montar um estúdio da rádio e instalou dez alto-falantes nos postes de iluminação pública, espalhados num perímetro de aproximadamente 800 metros, abrangendo três ruas, onde estão localizadas 
escolas, igreja, mercearias, posto de saúde e residências da comunidade. A ação fazia parte do Programa Caema Ambiental, instituído pela ONG (MESQUITA, 2017).

Sofrendo com a ausência do poder público, a Rádio Poste Caema foi instalada em uma sala da Igreja católica São Sebastião. Desde seu surgimento, a estrutura física da rádio foi composta por um computador, uma mesa de som e um microfone. Se por um lado a estrutura física da rádio permanece a mesma, em 2019, o número de alto-falantes duplicou, passando para vinte. Apesar da ampliação, a rádio ainda não se mantém no ar com regularidade, porque a comunidade não se apropriou da emissora.

Para que a rádio-poste funcionasse, o Instituto PES buscou envolver as lideranças comunitárias do bairro e a manutenção da parceria com a Universidade Federal do Maranhão (UFMA), por meio do curso de Jornalismo, que em dois momentos ofereceu capacitações aos moradores da Caema na expectativa de que se integrassem ao veículo de comunicação, usandoo como instrumento de mobilização social (MESQUITA, 2017).

Nos dois primeiros anos de funcionamento, a rádio-poste se restringia a veicular anúncios das programações religiosas e assuntos selecionados por alguns membros da igreja Católica da comunidade, sem preocupação com uma programação diária ou semanal. Somente a partir de 2014 a rádio passou a funcionar como campo de estágio e começou a ter uma programação sob a responsabilidade de dois estagiários do curso de Jornalismo da UFMA, campus Imperatriz. Após concluir o estágio eles passaram a receber uma ajuda de custo do Instituto PES para manter a estação no ar, com uma programação reunindo informações sobre o bairro, jornalismo, música, entrevistas e literatura. Mas por falta de recursos para manter as caixas de som em pleno funcionamento, a rádio deixou de funcionar em alguns momentos, durante o ano de 2016 (MESQUITA, 2017).

Nesse mesmo ano, a professora do curso de Comunicação da UFMA, Giovana Mesquita, criou o projeto de Extensão "Mistura de Saberes", que reuniu estudantes voluntários do curso de Jornalismo da Universidade Federal do Maranhão, sobretudo os que cursavam a disciplina Radiojornalismo. A missão era colocar no ar uma radiorrevista, trazendo à tona os problemas e também as potencialidades do local, por meio de entrevistas, reportagens e notas, ao mesmo tempo que incorporasse também poesias, música, quadros de histórias infantis, de culinária e de saúde. 
Os formatos (entrevistas, reportagens, curiosidades, música, poesia) seguiram uma categorização proposta por Barbosa Filho (2003, p. 138), para quem a radiorrevista está dentro do gênero especial, por ser um formato que não possui "uma função específica como dos outros gêneros, mas, sim, apresenta várias funções concomitantes. A este formato híbrido resolvemos atribuir para efeito classificatório a terminologia especial, incluindo-a num gênero multifuncional".

As primeiras edições das radiorrevistas produzidas pelos estudantes junto com a comunidade reuniram temáticas sobre consciência negra, Aids, enfrentamento da violência contra a mulher e a geração de emprego e renda no bairro da Caema. Com assuntos ligados à cultura, aos direitos humanos, à saúde, à educação e ao meio ambiente, o programa de rádio também tinha uma proposta de reconstituir a memória do bairro da Caema, inicialmente habitado por pescadores amadores e profissionais, que se utilizavam do rio Tocantins como fonte de renda (MESQUITA, 2017).

Em 2017, com a saída da coordenadora, que passou a trabalhar na Universidade Federal de Pernambuco, o projeto contou com a colaboração do professor de Televisão da UFMA, Vitor Belém, que tentou dar continuidade ao "Mistura de Saberes" até o ingresso da nova docente de Radiojornalismo da instituição, Izani Mustafá. Desde o segundo semestre de 2018, a docente se propôs a atualizar o projeto de extensão com o retorno da produção e apresentação do programa "Mistura de Saberes" na Rádio Caema, incorporando os estudantes de jornalismo da UFMA.

No final de 2018, com a expectativa de reativar a iniciativa com a produção de, pelo menos, três programas semanais, estudantes de Radiojornalismo aplicaram um questionário a 50 moradores para saber se desejavam que a rádio-poste funcionasse, em qual horário, e quais assuntos gostariam que fossem abordados na transmissão ao vivo. No entanto, por falta de recursos do Instituto PES e por problemas técnicos nas caixas de som, a emissora não funcionou. Em 2020, quando estava tudo alinhavado para o programa ir ao ar, surgiu a pandemia da Covid-19, que provocou a suspensão das atividades acadêmicas na UFMA. No entanto, a meta é que a rádio-poste inicie as transmissões regulares com a colaboração dos estudantes, dos voluntários da comunidade e dos bolsistas. 
Outro caso de rádio-poste, funcionando como prestação de serviços e também como campo de aprendizado, aconteceu em outubro de 2019. A Academia Imperatrizense de Letras cedeu espaço no $17^{\circ}$ Salão do Livro de Imperatriz (Salimp), para que estudantes de Radiojornalismo da UFMA colocassem no ar uma programação cultural e literária, durante os seis dias do evento. A professora da disciplina, Izani Mustafá, aceitou o desafio e os estudantes e estagiários se revezaram para fazer a cobertura jornalística, nos três turnos. Durante as emissões ao vivo, eles fizeram entrevistas com escritores, organizadores do evento, público em geral; deram informações e passaram sugestões de livros e autores para os frequentadores da feira.

\section{Considerações finais}

A revisão bibliográfica, a análise das leis números 10.872/2018 e 9.612/1998, referentes respectivamente às rádios-postes no Maranhão e às rádios comunitárias no Brasil, e o acesso a algumas experiências de emissoras alternativas no Maranhão contribuíram para o entendimento da função social e do papel relevante, sobretudo no Nordeste, das rádios comunitárias, tanto as do tipo poste, quanto as de frequência modulada.

Elas são fundamentais para uma comunicação local. Em algumas localidades, a rádioposte se constitui no único veículo que transmite informações noticiosas de interesse público, prestando um serviço e podendo contribuir para a formação do cidadão, além de ofertar algum tipo de entretenimento.

A importância da rádio-poste em uma comunidade, a exemplo da Caema, na cidade de Imperatriz (MA), como em tantos outros lugares do Brasil, é que ela acena efetivamente como uma possibilidade de democratização da comunicação nessa localidade, além de funcionar como promotora da cultura local.

Em Imperatriz, no Maranhão, tanto a Rádio Caema como a Rádio Salimp incorporaram a rádio-poste na perspectiva de informar, valorizar a cultura local e a educação. A Rádio Salimp foi pensada pela Academia Imperatrizense de Letras, e, durante os seis dias da feira literária, permitiu que os estudantes de Radiojornalismo, orientados pela professora, cuidassem da programação voltada aos conteúdos relacionados à literatura. 
Outro papel relevante das duas rádios, sediadas em Imperatriz, foi o de contribuir com a formação de estudantes do curso de Comunicação por meio de estágios e a partir de projetos de extensão e de pesquisa. Em qualquer uma dessas possibilidades dos jovens se integrarem à comunidade são ampliadas as trocas de experiências fora do ambiente acadêmico, visando, além da profissionalização, a revitalização dos laços entre a comunidade e a universidade.

Em 2020, quando o rádio no Brasil comemorou 101 anos, com as novas tecnologias e plataformas, impulsionadas pela internet, contribuindo para a reconfiguração desse importante veículo de comunicação, a rádio-poste se mantém atuante e relevante, cumprindo um importante papel social para centenas de comunidades espalhadas pelo território brasileiro.

\section{Referências}

ALMEIDA, Pedro Ivo Nunes. Nas ondas de Mar Vermelho: um estudo de caso da rádio poste "paz e liberdade" do interior de Alagoas. 2010. Monografia (Graduação em Comunicação Social) - Curso de Comunicação Social, Universidade Federal de Viçosa, Viçosa, 2010. Disponível em: https://www.jornalismo.ufv.br/wp-content/uploads/2018/06/PedroIvo.pdf. Acesso em: 19 abr. 2019.

ANATEL. Relatório Anual 2018. Agência Nacional de Telecomunicações. 2018. Disponível em:

https://sei.anatel.gov.br/sei/modulos/pesquisa/md_pesq_documento_consulta_externa.php?eE $\mathrm{P}-$

wqk1skrd8hSlk5Z3rN4EVg9uLJqrLYJw_9INcO5qCMSr1EMcIpgzizi6JB11ZfIGUkLQFuvnQ2rlXU4epBnwl_RtrJMm4TFmg79Z9fViw1qMyG2njP4-8SlBgOO. Acesso em: 8 jun. 2020 .

ARAÚJO, Ed Wilson Ferreira. Rádios comunitárias no Maranhão: histórias, avanços e contradições na luta pela democratização da comunicação. São Luís: EDUFMA, 2011.

ASA Brasil. A rádio poste da comunidade quilombola Maracujá, em Conceição do Coité, no território do sisal da Bahia. Asa Brasil. [S.d.]. Disponível em: http://www.asabrasil.org.br/26noticias/ultimas-noticias/10505-oficina-reforca-vinculo-de-criancas-e-adolescentes-com-aradio-poste-instalada-na-escola-rural-em-conceicao-do-coite. Acesso em: 19 abr. 2019.

ATLAS DA NOTÍCIA. Os desertos de notícias no Brasil. Projor, versão 3.0, fev. 2020. Disponível em: https://www.atlas.jor.br/desertos-de-noticia/. Acesso em: 11 jun. 2021.

BARBOSA FILHO, André. Gêneros radiofônicos: os formatos e os programas em áudio. São Paulo: Paulinas, 2003. 
BRASIL. Lei $\mathbf{n}^{0}$ 9. 612, de 19 de fevereiro de 1998. Disponível em: http://www.planalto.gov.br/ccivil_03/leis/19612.htm. Acesso em: 16 mar. 2019.

BROCK, Nils; MALERBA, João Paulo (org.). Rádios Comunitárias em tempos digitais. Reflexões sobre as transformações, inovações e desafios da mídia participativa. Rio de Janeiro: AMARC Brasil, 2017.

DOLCE, Júlia. Sob críticas de movimentos, lei que regulamenta rádios comunitárias completa 20 anos. Brasil de Fato, São Paulo, 16 fev. 2018. Disponível em: https://www.brasildefato.com.br/2018/02/16/sob-criticas-de-movimentos-lei-queregulamenta-radios-comunitarias-completa-20anos\#: :text=Antes\%20da\%20promulga\%C3\%A7\%C3\%A3o\%20da\%20legisla\%C3\%A7\%C 3\%A3o,5\%20mil\%20autorizadas\%20a\%20funcionar. Acesso em: 2 jun. 2020.

IBGE - INSTITUTO BRASILEIRO DE GEOGRAFIA E ESTATÍSTICA. João Lisboa. 2020. Disponível em https://cidades.ibge.gov.br/brasil/ma/joao-lisboa/panorama Acesso em:11 jun. 2021 .

KAPLÚN, Mário. El comunicador popular. Quito: CIESPAL, 1985.

KISCHINHEVSKY, Marcelo. Rádio e mídias sociais: mediações e interações radiofónicas em plataformas digitais de comunicação. Rio de Janeiro: Ed. Mauad X, 2016.

LÁZARO JÚNIOR, José. Brasil tem 4.607 rádios comunitárias; confira a relação por município e CNPJ. Livre.Jor. 2 jun. 2020. Disponível em: https://livre.jor.br/brasil-tem-4-607-radioscomunitarias-confira-a-relacao-por-municipio-e-cnpj/. Acesso em: 4 jul. 2021.

LUZ, Dioclécio Ferreira. Radiojornalismo nas rádios comunitárias: conceitos e práticas. 2011. Dissertação (Mestrado em Comunicação Social) - Programa de Pós-Graduação em Comunicação, Universidade de Brasília, Brasília, 2011.

LUZ, Dioclécio Ferreira. A arte de pensar e fazer rádios comunitárias. Brasília: [s.n.], 2007.

MALERBA, João Paulo. Rádios comunitárias no limite: crise na política e disputa pelo comum na era da convergência midiática. 2016. Dissertação (Mestrado em Comunicação e Cultura) - Programa de Pós-Graduação em Comunicação e Cultura, Universidade Federal do Rio de Janeiro, Rio de Janeiro, 2016. Acesso em: 15 mar. 2019.

MARANHÃO (Estado). Lei $\mathbf{n}^{0}$ 10. 872, de 19 de junho de 2018. Dispõe sobre a regulamentação do Serviço de Publicidade Alternativa de Linha Modulada, transmitida via equipamentos sonoros, no Estado do Maranhão. Disponível em: https://www.legisweb.com.br/legislacao/?id=361540. Acesso em: 17 mar. 2019.

MARANHÃO FILHO, Luiz. Memória do rádio. Olinda: Editorial Jangada, 1991. 
MESQUITA, Giovana Borges. Misturando saberes no interior do Maranhão: a experiência da rádio-poste da Caema. Revista Rádio-Leituras, v. 08, n. 02, p. 09-27, jul./dez. 2017. Disponível em: https://periodicos.ufop.br/radio-leituras/article/view/1030/896. Acesso em: 16 mar. 2019.

PERUZZO, Cicilia M. K. Comunicação nos movimentos populares: a participação na construção da cidadania. Petrópolis, RJ, Vozes, 1998.

PERUZZO, Cicilia M. K. Mídia regional e local: aspectos conceituais e tendências. Comunicação \& Sociedade, v. 26, n. 43, p. 67-84, $1^{\circ}$ sem. 2005. Disponível em: https://www.metodista.br/revistas/revistas-ims/index.php/CSO/article/view/8637/6170.

Acesso em: 25 abr. 2019.

PERUZZO, Cicilia M. K. Conceitos de comunicação popular, alternativa e comunitária revisitados e as reelaborações no setor. ECO-Pós, v.12, n.2, p. 46-61, mai/ago. 2009. Disponível em: https://revistas.ufrj.br/index.php/eco_pos/article/viewFile/947/887. Acesso em: 25 abr. 2019.

PERUZZO, Cicilia M. K. Rádios comunitárias no Brasil: da desobediência civil e particularidades às propostas aprovadas na CONFECOM. COMPÓS - ASSOCIAÇÃO NACIONAL DOS PROGRAMAS DE PÓS-GRADUAÇÃO EM COMUNICAÇÃO, 2010., Rio de Janeiro. Disponível em: compos.com.puc-rio.br/media/g6_cicilia_peruzzo.pdf. Acesso em: 25 abr. 2019.

PERUZZO, Cicilia M. K. VOLPATO, Marcelo. Rádio comunitária e liberdade de expressão no Brasil. Chasqui - Revista Latinoamericana de Comunicação, v. 109, p. 39-42, 2010. Disponível em: http://www.redalyc.org/articulo.oa?id=16057454004. Acesso em: 25 abr. 2019.

RADIOJORNAL Gameleira. Facebook. Disponível em: https://www.facebook.com/radiojornalgameleira/. Acesso em: 25 abr. 2019.

RADIOJORNAL Gameleira. Instagram. Disponível em: https://www.instagram.com/radiojornalgameleira/. Acesso em: 25 abr. 2019.

RIBEIRO, Milena de Castro. Rádio poste da Quadra: a participação dos moradores e as disputas sonoras em uma comunidade em Fortaleza. 2016. Dissertação (Mestrado de Comunicação e Linguagens) - Universidade Federal do Ceará, Fortaleza, 2016. Disponível em: http://www.repositorio.ufc.br/bitstream/riufc/17046/1/2016_dis_mcribeiro.pdf. Acesso em: 25 abr. 2019.

SANCIONADA lei que regulamenta rádio poste. Governo do Maranhão, 20 jun. 2018. Disponível em: https://www.ma.gov.br/sancionada-lei-que-regulamenta-radio-poste/. Acesso em: 17 mar. 2019. 
Submetido em: 20.06.2020.

Aprovado em: 19.02.2021. 